\title{
A Comparative Study of Abbreviated Heat Treatments for SAE 4130 Steel After Laser Welding ${ }^{1}$
}

\author{
Raquel Alvim de Figueiredo Mansur ${ }^{a}$, Caroline Cristine de Andrade Ferreira ${ }^{a}$, Isabela Atílio ${ }^{a}$ (1), \\ Sheila Medeiros de Carvalho ${ }^{a}$,Vagner Braga ${ }^{a}$, Rafael Humberto de Mota Siqueira ${ }^{a}$,
} Milton Sergio Fernandes de Lima ${ }^{a *}$ (1)

anstitute for Advanced Studies, Photonics Division, São José dos Campos, SP, Brasil

Received: April 21, 2020; Revised: May 21, 2020; Accepted: June 12, 2020

\begin{abstract}
It was verified that SAE 4130 steel plates crack when laser beam welded at room temperature (RT). To overcome this problem, this work proposes a high temperature (HT) laser welding in order to reduce the residual stresses and create a bainitic structure instead of a martensitic one. A conventional post-welding heat treatment (PWHT) had been used as a comparison for HT. The centerline crack disappeared after a heat treatment of both in-situ (HT) or after inserting in a furnace (PWHT) at $500{ }^{\circ} \mathrm{C}$ for 10 minutes. The finite element analyses indicated a residual stress reduction from 163.70 to $3.72 \mathrm{MPa}$ in the fusion zone (FZ) of the welds from RT to HT. The hardness obtained in FZ depends on the thermal cycle induced microstructure of the welds as $400 \mathrm{HV}, 340 \mathrm{HV}$ and $250 \mathrm{HV}$, for martensite (RT), tempered martensite (PWHT) and bainite (HT) micro-constituents. The proposed in-situ high-temperature laser beam welding method proved its usefulness to solve the center crack issue in SAE 4130 joints.
\end{abstract}

Keywords: Laser beam welding, SAE 4130 steel, heat treatment, hardening.

\section{Introduction}

A couple of reports dated about 70 years ago indicated the use of SAE 4130 steel in US space program components such as envelopes, pillars and combustion chambers ${ }^{1,2}$. The application of this alloy in airspace increased through the years and today some bleeding air tubes in commercial aircrafts are made of $i t^{3}$. Chemical and petrochemical industries also made a large use of this alloy because of the good strength and toughness, weldability and machinability. Additionally, SAE 4130 steel is considerably cheaper than high $\mathrm{Ni}$ and $\mathrm{Cr}$ alloys such as those classified as ultra-high strength steels ${ }^{4}$.

SAE 4130 is a low-alloy steel containing molybdenum and chromium as strengthening agents. The carbon content is around $0.30 \%$ and with this relatively low carbon addition the alloy is good from the weldability standpoint, once post-welding heat treatment is observed ${ }^{5}$. The alloy can be hardened by quenching from $900{ }^{\circ} \mathrm{C}$ in oil or water, but usually is tempered to attain a good balance between hardness and toughness ${ }^{6}$. According to ASM standard the tempering temperature range for this alloy ranges from 200 to $700^{\circ} \mathrm{C}$ for periods of a few hours ${ }^{6}$.

Although the weldability of SAE 4130 has proven to be relatively good, some problems have been reported such as solidification cracks ${ }^{7}$ and martensite brittleness and high residual stresses ${ }^{8}$. These problems have been present in

${ }^{1}$ This paper was presented in the $10^{\text {th }}$ Brazilian Congress on Manufacturing Engineering, August 2019, São Carlos / SP.

*e-mail milton@ieav.cta.br the oil\&gas industry when particular joint geometries are required, such as flange-to-pipe fillet weld, which has been one of the motivations for this work.

Souza et al. ${ }^{9}$ compared gas tungsten arc welding (GTAW) and laser beam welding (LBW) for the joining of SAE 4130 steel plates. According to these authors both fusion zones (FZ) were composed with martensite decorated dendrites attaining a maximum hardness of $650 \mathrm{HV}$. After tempering at $400{ }^{\circ} \mathrm{C}$ for two hours, the hardness in FZ dropped to approximately $450 \mathrm{HV}$. Although both welds are defect-free, GTAW is six times larger than LBW and the laser beam speed was $60 \mathrm{~mm} / \mathrm{s}$ compared to $1.65 \mathrm{~mm} / \mathrm{s}$ for the same $1 \mathrm{~mm}$ thick plate.

Oliveira et al..$^{10}$ studied solid state phase transformation in SAE 4130 steel using fiber laser heating. According to the authors, a maximum hardness of $400 \mathrm{HV}$ is obtained on the steel surface because of martensite transformation of the base material (BM) composed of ferrite and pearlite. This is the type of phase transformation expected in the heat-affected zone (HAZ) of welds.

In previous studies, the present authors proved the usefulness of an in-situ inductive heating of the base material during and after the laser beam interaction for controlling the volume fraction of martensite in $\mathrm{FZ}$ and HAZ. Braga et al. ${ }^{11}$ produced a bainitic fusion zone instead of a martensitic one when transformation-induced plasticity (TRIP) steels were laser welded at $500{ }^{\circ} \mathrm{C}$ and keeping isothermal for 10 minutes. These in-situ austempered welded sheets presented an outstanding behavior in cup-drawing tests. 
Lima et al. ${ }^{12}$ introduced the same concept for in-situ tempered laser welds for a $18 \% \mathrm{Ni}$ Maraging 300 steel. One problem raised by these authors is the chemical heterogeneities in FZ due to dendritic micro-segregation, which could not be solved itself by the inductive heating at $570{ }^{\circ} \mathrm{C}$. As a result, the tempering of martensite could not be accomplished in the same way of a conventional heat treatment. However, one common result for both steel alloys is the flatness of the hardness profile across different regions, BM, HAZ and FZ, after the in-situ treatment, resulting in higher toughnesses.

The objective of the present work is to investigate the possibility of in-situ heat treatment of a SAE 4130 steel plate during laser beam welding (LBW) in comparison with conventional LBW with and without post-welding heat treatment (PWHT). The microstructure and hardness of different weld routes will be analyzed in order to minimize weld defects and decrease hardness modulations in the plate.

\section{Materials and Methods}

SAE 4130 steels were supplied by Gerdau Aços Finos Piratini in the form of a prismatic bar with $50 \mathrm{~mm} \times 50 \mathrm{~mm}$ cross section. The bar was previously forged, normalized at $870{ }^{\circ} \mathrm{C}$ per 2 hours, slowly cooled in a furnace and stress relieved before cutting in a spark erosion machine. Each block was cut with $20 \mathrm{~mm}$ thickness and then ground to a surface finishing with a Ra of $3 \mu \mathrm{m}$. The chemical composition, as furnished, is presented in Table 1. The final base material microstructure is composed of ferrite and pearlite with a hardness of about $200 \mathrm{HV}$.

The laser workstation comprises a fiber laser (IPG Photonics, model YLR 2000), collimation and focusing optics (Optoskand SE) and a CNC x-y-z table. The bead-on-plate welds were realized by a single run of the beam at $1000 \mathrm{~W}$ laser power and $50 \mathrm{~mm} / \mathrm{s}$ speed with the focus on the upper surface. These parameters have been used in our lab to obtain a weld depth of nearly $2 \mathrm{~mm}$ in carbon steel, which is approximately the required depth for the designed flange-to-pipe fillet joint.

The laser weld experiments were realized in conditions of room temperature (RT) and high-temperature (HT). In the RT case, the specimen is welded in the usual way, but the HT case requires an external heating source. This was accomplished by an induction furnace specially conceived for the current experiment and reported elsewhere ${ }^{11}$. The temperature evolution of the specimen was recorded by a thermocouple (TC) soldered to the lower surface of the workpiece. The set point temperature in the induction power unit was controlled by the TC link. The specimen was placed at the center of the furnace and heated to the preset temperature of $500{ }^{\circ} \mathrm{C}$ and, after 3 minutes for equalization, the weld is done. The welded coupon was kept at this temperature for 10 minutes and the inductive power was shut off, allowing the piece to cool down to room temperature. Since the specimen was inserted $5 \mathrm{~cm}$ in the furnace opening, any gas shielding was possible, which had been set for the RT case as well.

A third set of experiments called post-weld heat treated (PWHT) were accomplished by heat treat the specimen immediately after welded in a furnace at $500^{\circ} \mathrm{C}$ per 10 minutes and then let cool down to room temperature in that furnace. This experiment was conceived as a direct comparison to the in-situ inductive heating (HT).

The temperature of $500{ }^{\circ} \mathrm{C}$ corroborates the work of Huang et al. ${ }^{13}$, although these authors suggest two hours of isothermal treatment for achieving a full release of residual stresses in electron beam welded SAE 4130 steel. The use of two hours instead of ten minutes is not possible in the current setup because the furnace position below the laser beam optics may damage the lens.

Calculations had been done in three ways. First, a thermodynamic equilibrium phases calculation using ThermoCalc software and FEDAT database was implemented ${ }^{14}$. Second, it was used a FORTRAN 77 source code for estimation of time-temperature-transformation from Peet and Bhadeshia authors called MUCG85 ${ }^{15}$. This software estimates diffusive (ferrite) and glissile (martensite) phase transformations for a given steel composition. Third, a finite element analysis (FEA) software called SysWeld from ESI-Group ${ }^{16}$, which have been used to estimate the thermo-mechanical and metallurgical transformations in welds for RT and HT conditions. The computer-aided design model resembles the actual workpiece and the nodes are refined around the laser beam pathway. SysWeld was applied to determine the thermal evolution and the stresses in FZ and HAZ as a function of time.

Light optical microscopy (LOM) was accomplished using an Imager2R Zeiss microscope from polished and etched specimens. The etching solution was Nital 2\% (2\% nitric acid in ethanol). A Hitachi TM-3000 was used for scanning electron microscopy (SEM) in the same etched surfaces. A FutureTech FM800 microhardness tester had been used to obtain the hardness profile of different regions around FZ. The load was $100 \mathrm{gf}$, the dwell time was 10 seconds and the distance between the indentations was $100 \mu \mathrm{m}$.

\section{Results and Discussion}

\subsection{Calculations}

According to the Thermocalc Software (Version L, database FEDAT) solidus temperature of the current composition (Table 1) is $1454.98^{\circ} \mathrm{C}$ and onset of the ferrite transformation from austenite under equilibrium (A1) is $794{ }^{\circ} \mathrm{C}$. Because of the large quantity of solutes the phase balance is complex below A1. At $715^{\circ} \mathrm{C}$, for example, the equilibrium condition

Table 1. Chemical composition of the base material (wt.\%; Fe as the balance).

\begin{tabular}{ccccccccccc}
\hline $\mathrm{C}$ & $\mathrm{Si}$ & $\mathrm{Mn}$ & $\mathrm{P}$ & $\mathrm{S}$ & $\mathrm{Cu}$ & $\mathrm{Cr}$ & $\mathrm{Mi}$ & 0.15 & 0.25 \\
\hline 0.280 & 0.29 & 0.80 & 0.007 & 0.0100 & 0.10 & $\mathrm{As}$ & $\mathrm{Sb}$ & $\mathrm{N}$ \\
\hline $\mathrm{W}$ & $\mathrm{V}$ & $\mathrm{Nb}$ & $\mathrm{Co}$ & $\mathrm{Al}$ & $\mathrm{Sn}$ & 0.008 & 0.006 & 0.0026 & 0.0043 \\
\hline 0.0038 & 0.026 & 0.026 & 0.01 & 0.022 & 0.008 & \\
\hline
\end{tabular}


gives $94.8 \%$ ferrite, $3.6 \%$ cementite and $1.6 \% \mathrm{M}_{23} \mathrm{C}_{6}$ phase. The $\mathrm{M}_{23} \mathrm{C}_{6}$ phase, with $\mathrm{M}$ meaning a transition metal, has the following stoichiometry $\mathrm{Fe}-7.5 \% \mathrm{Mo}-2.3 \% \mathrm{Mn}-1.5 \% \mathrm{Cr}-$ $0.07 \% \mathrm{Ni}-5.2 \% \mathrm{C}$ (in mass). Hopefully the kinetics of the carbides formation in SAE 4130 steel are sufficiently low to state the ferrite as the product phase from austenite, or alternatively, an athermal martensite glissile transformation appears at high cooling rates ${ }^{6}$.

It is reported that, during rapid quenching, this steel undergoes a martensitic transformation from austenite and the martensite start (Ms) temperature. Among the various methods to calculate Ms temperature, the Andrews formalism is followed here ${ }^{17}$, which gives a Ms $=372{ }^{\circ} \mathrm{C}$ for the composition given in Table 1 . This value corroborates the ASM metals handbook reported value ${ }^{6}$.
The other phase transformations of interest are the Widmanstatten ferrite and bainite start temperatures below A1 and above Ms. For these, Peet and Bhadeshia algorithm was used $^{15}$ together with the alloy composition given in Table 1. Figure 1 presents the response function of the different micro-constituents as a function of temperature and time considering isothermal conditions. The approach here is the onset curve of time-temperature-transformation (TTT) reaction, i.e. the begin of a given diffusive transformation, is valid for continuous-cooling-transformation (CCT) from solidification as in the present case. The time invariant transformations A1 and $\mathrm{Ms}$ are plotted as horizontal lines, together with ferrite bainite (B) and Widmanstatten ferrite (F) start temperatures.

The RT and HT curves in Figure 1 are the cooling curve estimated by finite element analyses (FEA). The TC curve is

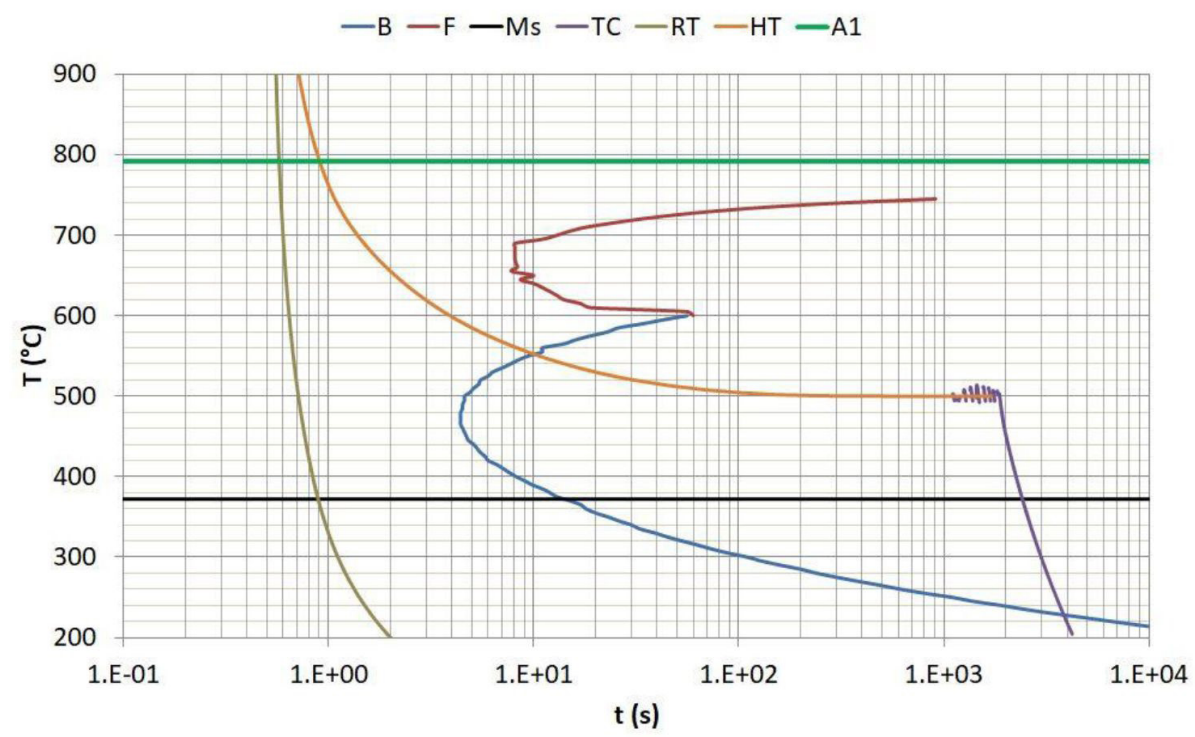

Figure 1. Response functions (temperature versus time) of the micro-constituents for the SAE 4130 steel.

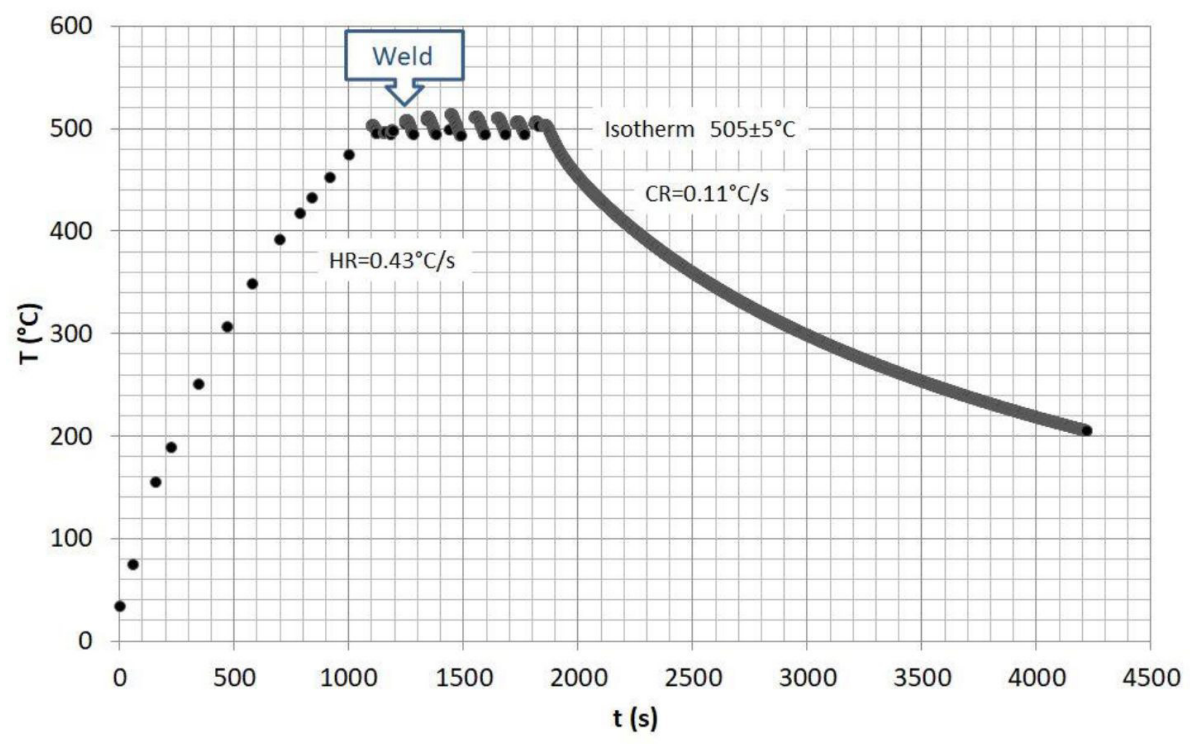

Figure 2. Temperature measurement of the thermocouple as a function of time. The laser weld start time is marked by an arrow. The isotherm temperature, heating rate (HR) and cooling rate (CR) are presented. 
the thermocouple record after the laser weld. The complete TC curve is presented in Figure 2 including the heating, isothermal and cooling regimes. The data scattering around the isothermal stage is due to the current relay switching around the preset temperature. The measured isothermal temperature after the laser beam interaction was $505 \pm 5^{\circ} \mathrm{C}$ and the heating and cooling rates were $0.43{ }^{\circ} \mathrm{C} / \mathrm{s}$ and $0.11^{\circ} \mathrm{C} / \mathrm{s}$, respectively, for the range $300-500^{\circ} \mathrm{C}$. According the response function plot of Figure 1, the heating and cooling rates are sufficiently high to avoid phase transformations in the base material composed of pearlite and ferrite. Consequently, these micro-constituent and their characteristic mechanical properties, such as elastic moduli might keep unchanged during heating and cooling periods.

FEA calculations using the software SysWeld (Esi-Group) started with the solid with the same dimensions of the specimen and a mesh size compatible to the laser weld. The exact SAE 4130 physical properties are missing in the software library, therefore a similar steel (SAE A36) was considered instead. The solid model is considered to follow the temperature profile given in Figure 2, including the beam interaction instant (weld). The fusion zone (FZ) is considered to be bounded by the solidus given by the Thermocalc calculations. The nodes are free to expand and contract as an unclamped solid. As the absorptivity of the laser beam in the material is unknown, the experimental weld dimensions were used as calibration, and then its value was fixed as 0.85 . This value agrees with the literature for the same laser and similar steel substrates ${ }^{18}$.
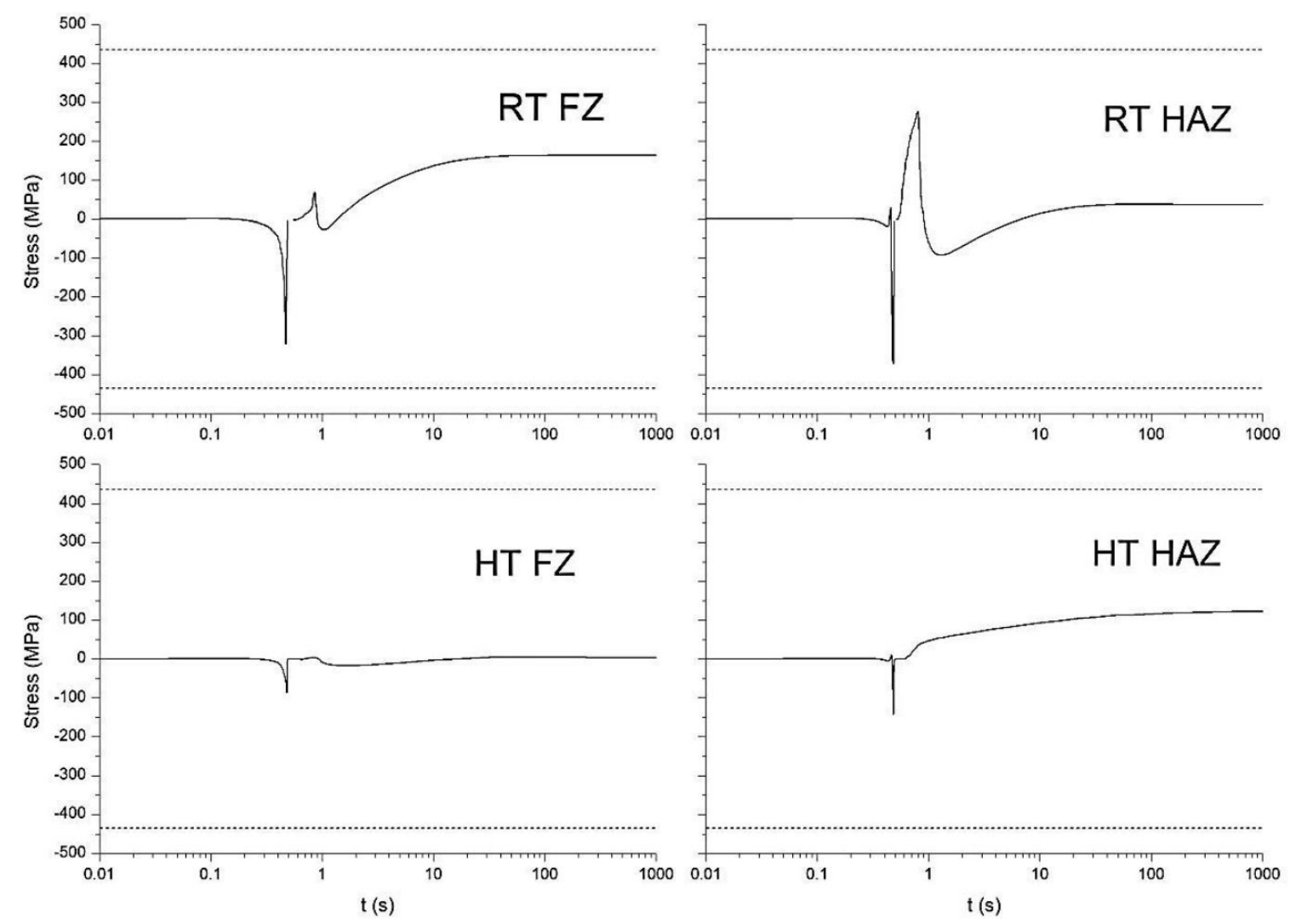

The curves RT and HT in Figure 1 are the FEA estimations in the middle of FZ for room temperature and high temperature conditions, respectively. As can be seen the RT curve strikes the Ms curve 0.9 seconds after the weld denoting a tendency for martensitic transformation of austenite.

As a consequence of an external heating, the HT curve attained the bainite ferrite start temperature 10 seconds after the weld and remained in this field for approximately 2000 seconds. As the B curve in Figure 1 is an indicator of starting diffusive transformation it is unclear the volume fraction of bainitic ferrite from austenite. However, as the transformation takes place, the Ms temperature should drop continuous ${ }^{17}$ and the rest of the austenite can be retained at room temperature. The reason for austenite stabilization in room temperature is the segregation of gammagenic elements to the residual austenite, as already reported in the literature ${ }^{19,20}$. Of course, the calculations considers a homogeneous parent phase (austenite) which could be inaccurate for as as-solidified weld bead. Nevertheless, as reported before ${ }^{12}$, the micro-segregation in between dendrite branches could be unsolubilized during the heat treatments.

Another result of the FEA calculations, it is the thermo-mechanical evolution of solid elements of the component with time. It is opportune to compare the residual stresses in RT and HT conditions, as estimated by simulation and presented in Figure 3, because direct experimental results are difficult to obtain. Only RT and HT conditions are presented in Figure 3 because PWHT stresses cannot be calculated in the present FEA software. The estimated

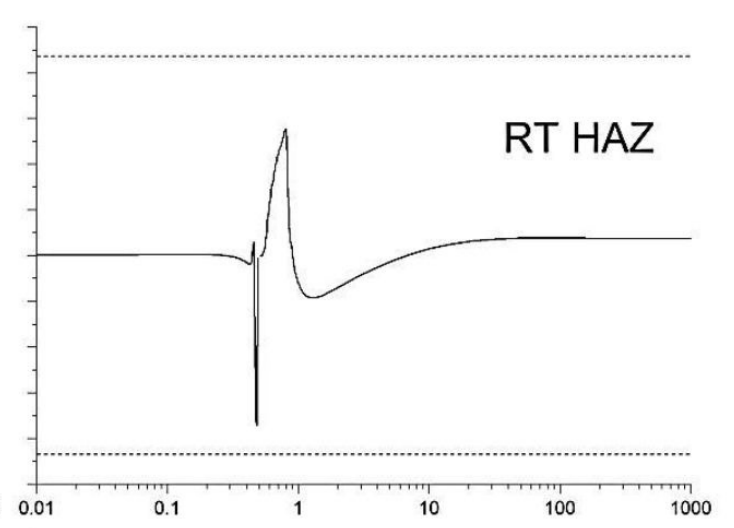

Figure 3. FEA results of the stress as a function of time for room temperature (RT) and high temperature (HT) welds in the fusion zone (FZ) and heat-affected zone (HAZ). 
stresses were shown in the fusion (FZ) and heat-affected (HAZ) zones of each condition RT and HT. The dotted lines bounds the yield strength of the alloy normalized at $870{ }^{\circ} \mathrm{C}$ as $-/+435 \mathrm{MPa}^{21}$. Therefore, the regions above and below the dotted lines entail plastic deformation of the solid.

As the heat source approaches to the volume of interest at the center of the weld bead, before melting, the rapid heating induces compressive forces due to expansion which almost attains the yield point of the steel for RT welds in both FZ and HAZ (Figure 3). During the FZ liquid phase the stresses are virtually zero and then rise quickly, according to the thermal gradient, dendritic coalescence and phase transformation from austenite to martensite. The magnitude of these stress rates is much lower at HT because of the low thermal gradient and absence of martensite transformation. After $1000 \mathrm{~s}$ the residual stresses are 163.70, 36.52, 3.72 and $122.31 \mathrm{MPa}$, for RT-FZ, RT-HAZ, HT-FZ and HT-HAZ, respectively. Although it is expected the FZ stresses are reduced from $\mathrm{RT}$ to $\mathrm{HZ}$, the HAZ follows the opposite way. The explanation for this is the extension of HAZ in HT, much wider compared to RT, with the corresponding increase in tractive forces upon cooling. It should be noted that the model considers the initial BM as stress-free. Huang et al. ${ }^{13}$ work on electron beam welded SAE 4130 indicated a maximum residual stress in $\mathrm{BM}$ of $177 \mathrm{MPa}$ and $392 \mathrm{MPa}$ in RT FZ (in modulus). This indicates that the BM stress state must amplify the weld residual stresses with deleterious effect in the toughness. Huang et al. ${ }^{13}$ also shown that after a PWHT at $530{ }^{\circ} \mathrm{C}$ per 2 hours the residual stress in $\mathrm{FZ}$ dropped to $98 \mathrm{MPa}$, indicating the importance of heat treatments of SAE4130 welded components.

\subsection{Microstructure}

A general view of representative weld beads and the surroundings are presented in Figure 4. Figure 4a shows a typical keyhole weld for the RT condition with a $0.6 \mathrm{~mm}$ width at top and $2.1 \mathrm{~mm}$ penetration from the upper surface. The HAZ, marked by a darkened region next to the fusion line, varies with the depth, but attained a maximum of $0.2 \mathrm{~mm}$. In Figure $4 \mathrm{a}$ it is also visible a central crack from top to bottom. Figure $4 \mathrm{~b}$ presents the weld with a post-welding heat treatment (PWHT) just after the laser interaction. The width and depth of 0.6 and $2.0 \mathrm{~mm}$, respectively, are similar to the RT case (Figure 4a), however any crack could be noticed. This fact indicated that the crack propagates well after solidification disagreeing from Souza and Paranhos ${ }^{7}$ findings. A possible explanation for the crack is the formation of small liquation pores near to the weld centerline (Figure 4a) followed by a growth induced by the local residual stresses. The maximum residual stresses in RT FZ condition (Figure 3) are attained after about 1000 seconds, but the workpiece was inserted in the furnace few seconds after the weld. This might be the reason PWHT welds are defect-free. Figure 4c is a macrograph of the HT condition where the width and depth as 0.9 and $1.9 \mathrm{~mm}$, respectively. The wide top of the weld, compared to Figure $4 \mathrm{a}$ and $4 \mathrm{~b}$, was associated with an increase in the plasma density for the heated substrate, as can be noticed during the experiment. The plasma was stronger due to an increase in laser-matter absorptivity in a hot substrate with an overall effect of the beam defocusing, thus
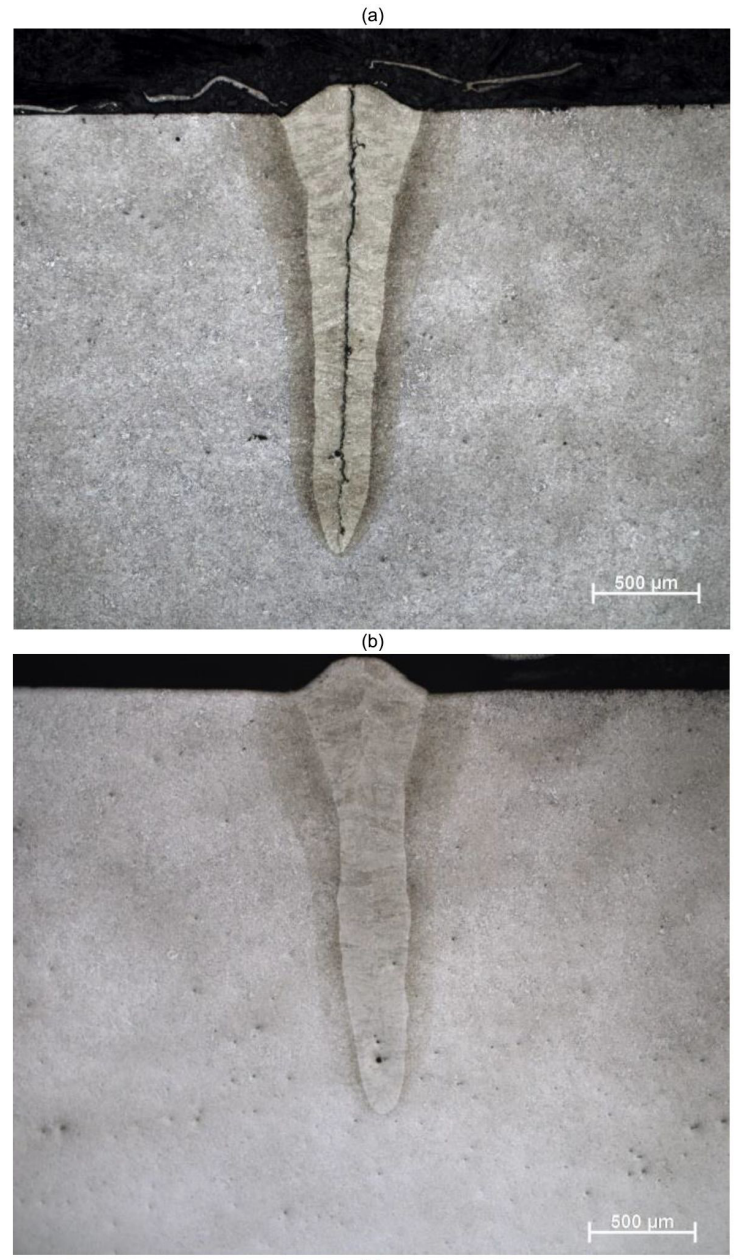

(c)

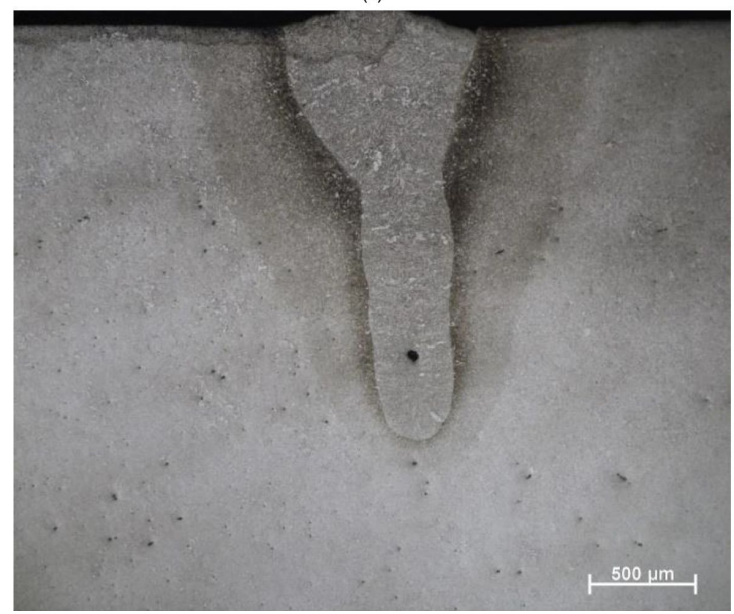

Figure 4. Optical macrographs of the welds: (a) RT; (b) PWHT and (c) HT.

increasing the width at the top and decreasing the penetration. The effect is enhanced by the absence of gas shielding during the beam interaction. The HAZ length doubles compared to the RT condition, corroborating the estimations of the FEA stress increase in this region (Figure 3 ).

The region around the middle in Figure 4a is presented in Figure 5 using SEM. A $10 \mu \mathrm{m}$ wide crack is visible together 


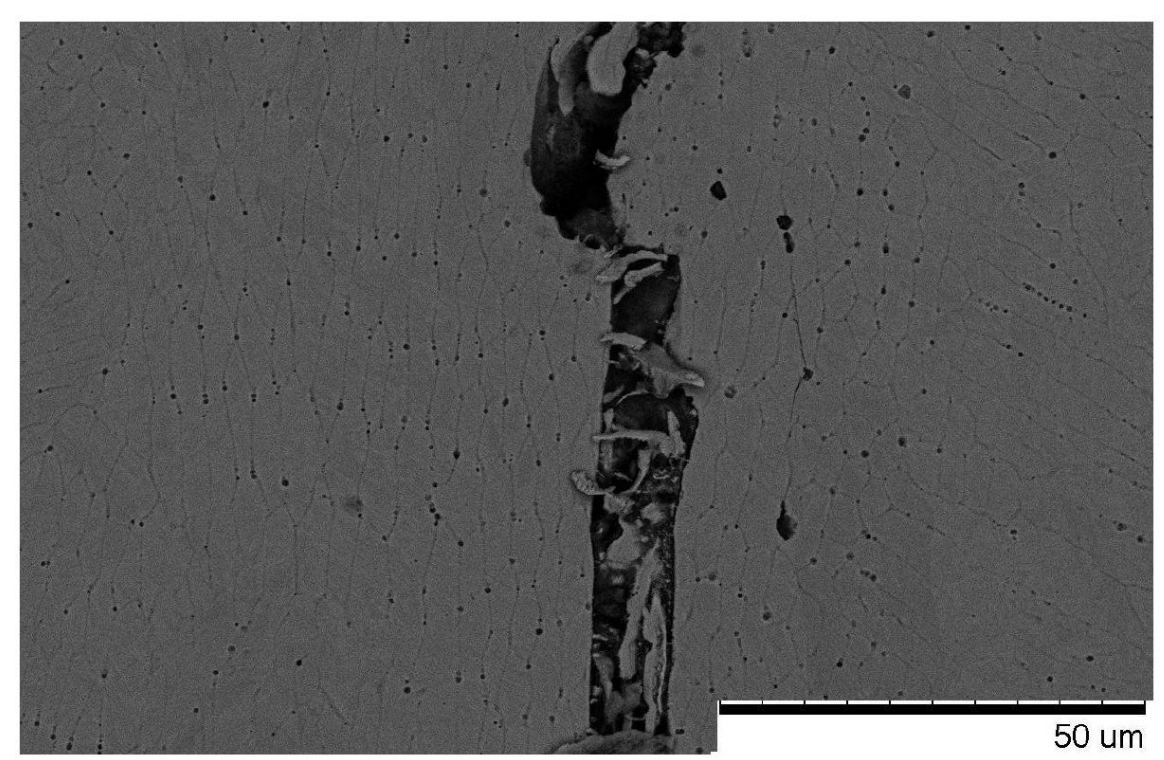

Figure 5. Scanning electron microscopy image of the region near to the center of RT weld (Figure 4a).

(a)

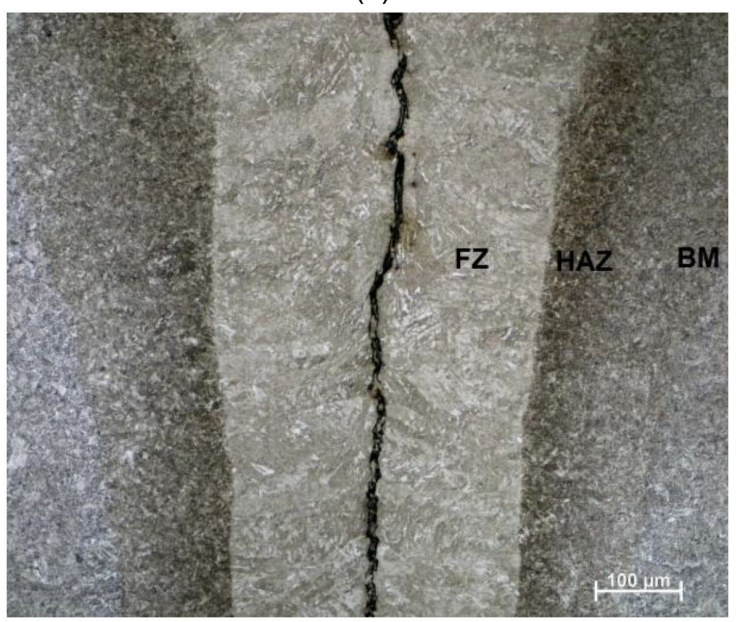

(b)

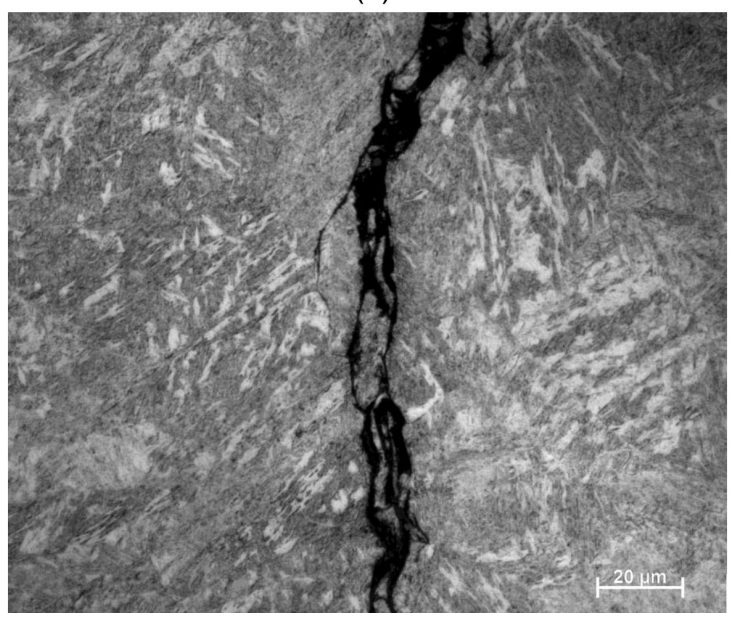

Figure 6. (a) Optical microscopy (Nital etch) of the RT weld. (b) a close look in FZ. with some debris and a cellular microstructural pattern. The width of the cells near to the crack are $3.8 \pm 0.6 \mu \mathrm{m}$ and height of $11 \pm 3 \mu \mathrm{m}$. Some facts indicate the crack occurred in solid-state (cold crack): a) The inter-cellular residue is very thin, below $0.5 \mu \mathrm{m}$, indicating a low micro-segregation; b) The crack borders are sharp and transverse the cells, i.e. the crack did not follow the mushy path due to the macro-segregation in the weld centerline; c) debris are faceted and d) PWHT weld did not show a crack (Figure 4b).

Phillips and Jordan ${ }^{22}$ associated the intrinsic brittleness of SAE 4130 to liquation cracking. These authors indicated the coalescence of many pores in the heat-affected zone of the welded steel to the premature rupture of the joints. Two questions must be considered here in comparison to these authors: On one hand, the HAZ in LBW is so small that a given liquation sub-zone should be hard to consider. On the other hand, many pores are observed in between the dendrites in the FZ (Figure 5). Therefore, the linear distribution of pores conjugated to tensile stresses may be the cause of the centerline crack observed.

Figure 6a shows an optical microscopy image comprising $\mathrm{BM}, \mathrm{HAZ}$ and FZ. The fusion zone is mainly martensitic, as shown in Figure 6b. The martensite features and cell structure are compatible with those reported by Li et al. for additive manufactured beads of the same alloy ${ }^{23}$.

Figure 7 shows some LOM images near the center of FZ of PWHT and HT welds. Figure 7a presents the different zones in a PWHT weld showing approximately the same features of the RT welds (Figure 6a). A grain boundary ferrite (GBF) bounding a pearlite micro-constituent is visible at upper left of Figure 7a indicating the base material remained approximately the same after PWHT as previewed before. A closer look at FZ of PWHT weld (Figure 7b) indicated the presence of tempered martensite. Some of the martensite plates seem to be coarser than the original RT martensite. Tempering at this temperature causes the formation of cementite, and, if strong carbide-forming elements are 
(a)

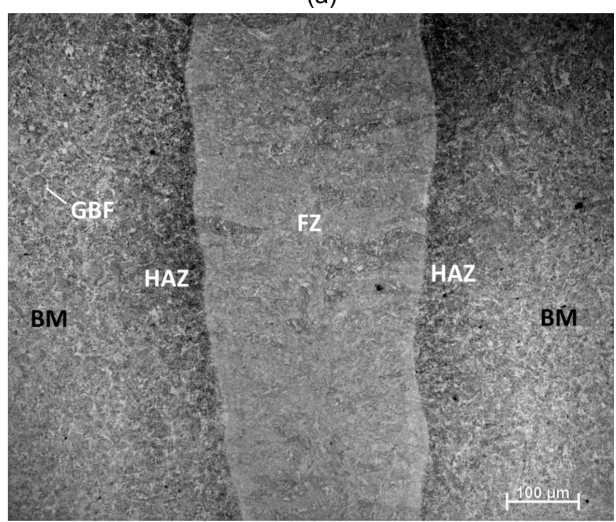

(b)

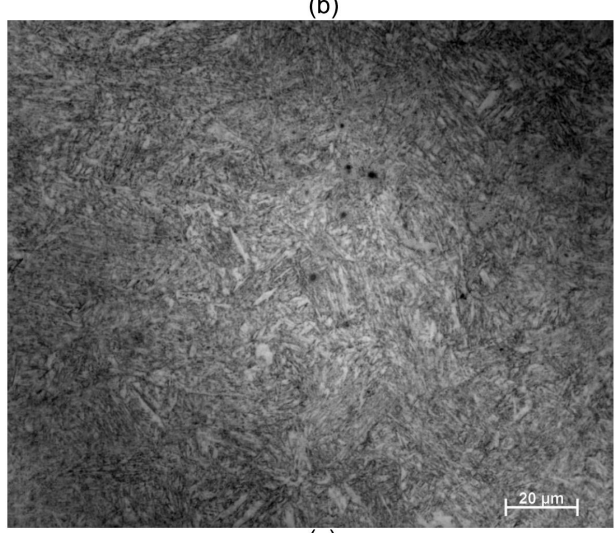

(c)

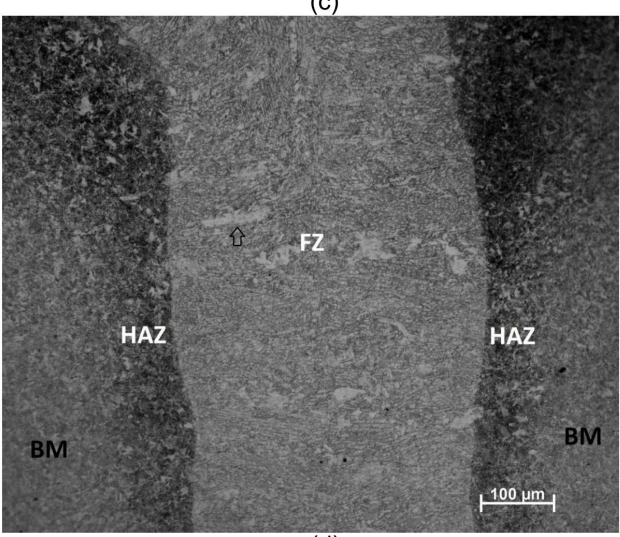

(d)

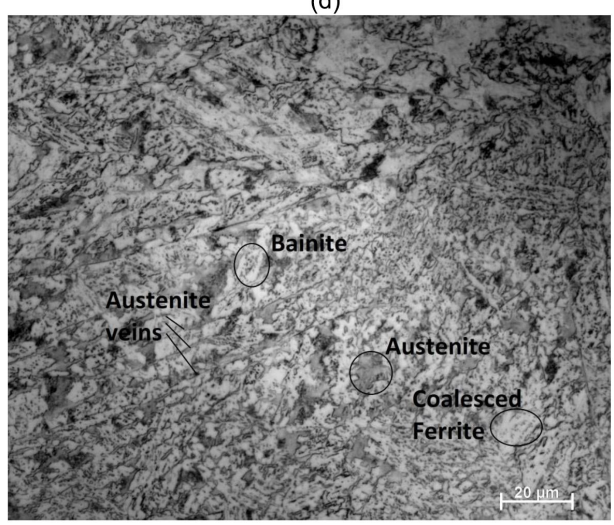

Figure 7. LOM images of selected regions (Nital etched): (a) PWHT middle of the weld. (b) PWHT ZF. (c) HT middle of the weld. (d) HT ZF. present, alloy carbides ${ }^{24}$. Concurrently, the laths or plates coarsen and the dislocation density is reduced by recovery mechanisms. In addition, retained austenite transforms to mixtures of cementite and ferrite between martensite laths and plates. The carbides formed by high-temperature tempering (Figure $7 b$ ) are much coarser than the transition carbides and are present at residual martensite interfaces and dispersed within the ferrite of the tempered martensite ${ }^{25}$.

The microstructure of HT welds (Figure 7c) differs somewhat of PHTW welds (Figure 7a) because of the shape and dimensions of ferrite. As can be seen in Figure 7c, some ferrite plates are relatively large such as that signed by an arrow, where the length was $90 \mu \mathrm{m}$ and the width $20 \mu \mathrm{m}$. According to previous studies ${ }^{26}$, the high temperature laser welding can result in some degree of ferrite coalescence provided the crystallographic misfit angle between the platenets is relatively small. Coalesced bainite begins as a series of adjacent, identically oriented platelets of ferrite only marginally separated by austenite films. These early stages involve the development of the nucleus into a particle which can grow rapidly, thus permitting the partitioning of carbon. As the platelets lengthen, and assuming there is nothing to stop them from lengthening, they accelerate and coalesce. The carbon is then trapped in the ferrite, either to precipitate later or to partly partition into the residual austenite. Such coalescence can only occur when the driving force available is sufficient to sustain the greater strain energy associated with the coarser plates ${ }^{27}$. A closer observation of FZ in HT welds (Figure 7d) seems to corroborate these assumptions. The image in Figure $7 \mathrm{~d}$ shows the bainite and retained austenite phases as a result of partition during the isothermal growth phase (Figure 2) and in agreement with the response function of bainite (Figure 1). Along with these features, the coalesced ferrite is shown as a result of platelet fusion and the austenite veins are a direct evidence that inter-cellular segregation (Figure 5) is rich in austenite stabilizers such as $\mathrm{Mn}$ (Table 1).

\subsection{Hardness}

The Vickers hardness profiles as a function of the distance from the weld centerline are presented in Figure 8. As discussed before using the data plot in Figure 2, the heating and cooling regimes in the base material after heat treatment, HT or PWHT, did not change the microstructure of the base material. As a consequence, the base line of HV, left and right data in Figure 8, remains at approximately 200 HV. The FZ hardness depends on the weld methodology and attained 400, 340 and $250 \mathrm{HV}$ for RT, PWHT and HT conditions, respectively.

The RT FZ hardness level is well below the Souza Neto et al. ${ }^{9}$ reported values, $400 \mathrm{HV}$ compared to $650 \mathrm{HV}$. However, these authors had worked in thin sheets $(1 \mathrm{~mm}$ thick) with a higher speed and less beam power, where the differences in HV should come on. The RT hardness level is also slightly below that reported by Huang et al. ${ }^{13}$ for electron beam welded SAE 4130. However, the PWHT HV values in FZ are similar to those reported by these authors. The noticed disparities can be associated with the different chemical compositions and the FZ dimensions. The weld 


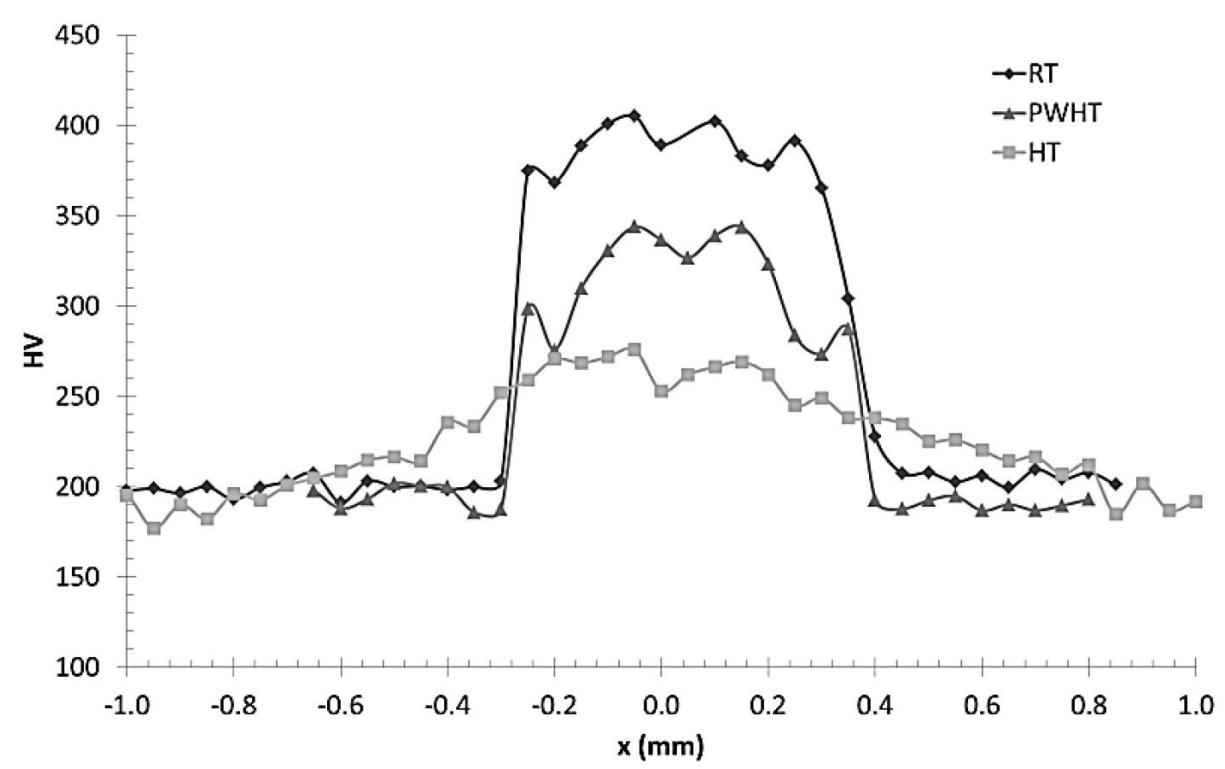

Figure 8. Vickers hardness HV profile as a function of the distance (x) from the centerline of the weld.

width in the present work was approximately $0.5 \mathrm{~mm}$ compared to $3 \mathrm{~mm}$ of Huang et al. study ${ }^{13}$.

It is noted, in the HT curve of Figure 8 , a softer transition between the FZ and BM, i.e. from 250 to $200 \mathrm{HV}$. The flatten shape of the HV curve in HT conditions induces less stress concentrator which is responsible for premature failure of fatigued components ${ }^{28}$.

\section{Conclusions}

The present work studied the possibility of in-situ heat treatment during laser beam welding (HT) and compare to room-temperature (RT) and post-weld heat treated (PWHT) welds for a SAE 4130 block.

The HT welds were accomplished by inductive heating of the sample before and after the laser interaction with an isothermal temperature of $500{ }^{\circ} \mathrm{C}$ for 10 minutes, followed by slow cooling $\left(0.11^{\circ} \mathrm{C} / \mathrm{s}\right)$.

The PWHT welds were done using the same time and temperature, however the treatment is done few seconds after the laser track in a preheated furnace.

The RT ordinary welds and the others were performed at $1000 \mathrm{~W}$ laser beam power and $50 \mathrm{~mm} / \mathrm{s}$ speed with the focus on the top and without a shielding gas.

The weld depth attained nearly $2 \mathrm{~mm}$ in all conditions, and the top width of the HT condition was fairly wider than the other conditions because of the plasma incandescence.

The welds obtained on RT condition shown a central crack, from top to bottom of the bead, and a martensitic structure.

According to the finite element analyses (FEA) and microstructural analyses these cracks can be associated with the inter-cellular pores alignment and an excessive residual stress.

According to the FEA, the residual stress in the fusion zone (FZ) of RT welds is $163.70 \mathrm{MPa}$. This stress level is much higher than the FZ residual stress after HT weld, 3.72 MPa.
The centerline cracks were not observed in PWHT and HT welds. Therefore, it was concluded the cold crack must have some time for growing.

The residual stresses in the heat-affected zone (HAZ) of HT welds are much higher than in RT welds, 36.52 compared to $122.31 \mathrm{MPa}$, which have been linked to the large extension of the HAZ when the substrate was pre-heated.

In terms of microstructure, PWHT welds were characterized by tempered martensite and HT welds with bainite and residual austenite, in agreement with the current models.

The bainite in HT welds shown occasional coalescence as a result of the fusion of neighboring ferrite platenets.

The HT residual austenite presents two morphologies, as islands where the ferrite phase growth segregates austenitizing elements and as veins where the primary micro-segregation of the cells segregated solutes.

The hardness profiles followed the microstructural characteristics and presented high $(400 \mathrm{HV})$, medium (340 HV) and low (250 HV) levels for the fusion zone in RT, PWHT and HT conditions, respectively.

The flat shape of the HT hardness profile throughout the different zones indicates a tendency for less stress concentrators.

The proposed in-situ high-temperature laser beam welding method proved its usefulness to solve the center crack issue in SAE 4130 joints.

\section{Acknowledgements}

RAFM, CCAF and IA thanks Coordenação de Aperfeiçoamento de Pessoal de Nivel Superior (CAPES) for the graduate scholarships. VB thanks São Paulo Research Foundation FAPESP for the doctoral scholarship (grant\# 2018/23884-5). RHMS thanks São Paulo Research Foundation FAPESP for the postdoctoral scholarship (grant\# 2019/25229-7). The authors also acknowledge the financial support of São Paulo Research Foundation FAPESP grant\# 2016/11309-0. 


\section{References}

1. Illg W. Fatigue tests on notched and unnotched sheet specimens of 2024-T3 and 7075-T6 aluminum alloys and of SAE 4130 steel with special consideration of the life range from 2 to 10,000 cycles. NACA-TN-3866 technical report. Washington: NASA; 1956 [cited 2020 Apr 17]. Available from: https://ntrs. nasa.gov/archive/nasa/casi.ntrs.nasa.gov/19930084699.pdf

2. MacGregor CW, Grossman N. Effects of cyclic loading on mechanical behavior of 24S-T4 and 75S-T6 aluminum alloys and SAE 4130 steel. NACA-TN-2812 technical report. Washington: NASA; 1952 [cited 2020 Apr 17]. Available from: https://ntrs. nasa.gov/search.jsp?R=19930083556

3. MD Exports LLP. 4130 Aircraft Tubing -AISI 4130 Aircraft Steel (AMS 6345/AMS 6346/AMS 6350). Mumbai: MD Exports LLP; 2020 [cited 2020 Apr 17]. Available from: http:// www.4130pipefittings.com/aisi-4130-alloysteel/4130-alloysteelpipes-tubes-tubing/alloysteel-tubing-type-4130-aircraft-tubing/ index.html

4. GRANTA EduPack. CES EduPack. ANSYS. 2020 [cited 2020 Apr 17]. Available from: https://grantadesign.com/education/ ces-edupack/

5. Still JR. Welding of AISI 4130 and 4140 steels for drilling system. Weld J. 1997;76(6):500908.

6. ASM International. ASM Metals HandBook. Vol. 4 - Heat Treating. Materials Park, Ohio: ASM International; 1994.

7. Souza ME, Paranhos R. Metallurgical evaluation of austenitic stainless surfacing welding on SAE 4130 steel. Welding international. 2016;30(8):581-589.

8. Rybakov D. Post weld heat treatment of welded low alloyed steel pipes: use of AISI 4130 steel in hydrogen sulfide environment and its post weld heat treatment conditions [dissertation]. Noruega: University of Agder; 2019. [cited 2020 Apr 17]. Available from: https://uia.brage.unit.no/uia-xmlui/handle/11250/2617141

9. Souza F No, Neves D, Silva OMM, Lima MSF, Abdalla AJ. An analysis of the mechanical behavior of AISI 4130 steel after TIG and laser welding process. Procedia Eng. 2015;114:181-8.

10. Oliveira RJB, Siqueira RHM, Lima MSF. Microstructure and wear behaviour of laser hardened SAE 4130 steels. Int J Surface Sci Eng. 2018;12(2):161-70.

11. Braga V, Mansur RAF, Siqueira RHM, Lima MSF. Formability of in-situ austempered transformation-induced plasticity steels after laser beam welding. Soldag Insp. 2018;23(3):402-12.

12. Lima MSF, Siqueira RHM, Carvalho SM, Abdalla AJ. Hardening effects of in-situ aging for a laser welded maraging steel. Journal of Aircraft and Spacecraft Technology. 2019;3:237-47. http:// dx.doi.org/10.3844/jastsp.2019.237.247.

13. Huang C, Pan Y, Chuang T. Effects of post-weld heat treatments on the residual stress and mechanical properties of electron beam welded sae 4130 steel plates. J Mater Eng Perform. 1997;6:61-8.

14. Andersson JO, Helander T, Höglund L, Shi PF, Sundman B. Thermo-calc and DICTRA, computational tools for materials science. Calphad. 2002;26:273-312.

15. Materials Science \& Metallurgy. MAP Program MAP_STEEL_ MUCG83. Cambridge: University of Cambridge; 2020 [cited 2020 Apr 17]. Available from: https://www.phase-trans.msm. cam.ac.uk/map/steel/programs/mucg83.html

16. ESI Group Headquarters. Get is right. 2020 [cited 2020 Apr 17]. Available from: https://www.esi-group.com/software-solutions/ virtual-manufacturing/welding-assembly/esi-sysweld

17. Andrews KW. Empirical formulae for the calculation of some transformation temperatures. J Iron Steel Inst. 1965;203:721-7.

18. Correard GCC, Miranda GP, Lima MSF. Development of laser beam welding of advanced high-strength steels. Int J Adv Manuf Technol. 2016;83:1967-77.

19. Brandt ML, Olson GB. Bainitic stabilization of austenite in low alloy sheet steels. Ironmak Steelmak. 1993;20(5):55-60.

20. Behera AK, Olson GB. Prediction of carbon partitioning and austenite stability via non-equilibrium thermodynamics in Quench and Partition (Q\&P) steel. JOM. 2019;71(4):1375-85.

21. ASM Aerospace Specification Metals, Inc. ASM Material Data Sheet. Pompano Beach: ASM Aerospace Specification Metals, Inc.; 2020 [cited 2020 Apr 17]. Available from: http://asm. matweb.com/search/SpecificMaterial.asp?bassnum $=\mathrm{m} 4130 \mathrm{r}$

22. Phillips RH, Jordan MF. Weld heat-affected zone liquation cracking and hot ductility in high-strength ferritic steels. Met Technol. 1977;4(1):396-405.

23. Li X, Tan YH, Willy HJ, Wang P, Lu W, Cagirici M, et al. Heterogeneously tempered martensitic high strength steel by selective laser melting and its micro-lattice: processing, microstructure, superior performance and mechanisms. Mater Des. 2019;178:107881.

24. Wu YX, Sun WW, Gao X, Syles MJ, Arlazarov A, Hutchinson CR. The effect of alloying elements on cementite coarsening during martensite tempering. Acta Mater. 2020;183:418-37.

25. ASM International. ASM Metals HandBook. Vol. 1 - Properties and Selection Irons Steels and High Performance Alloys. Materials Park, Ohio: ASM International; 1994.

26. Lima MSF, Gonzales D, Liu S. Microstructure and mechanical behavior of induction-assisted laser welded AHS steels. Weld J. 2017;96(10):376S-88S.

27. Bhadeshia HKDH, Keehanz E, Karlssonz L, Andren HO. Coalesced bainite. Trans Indian Inst Met. 2006;59:689-94.

28. Mochizuki M. Control of welding residual stress for ensuring integrity against fatigue and stress-corrosion cracking. Nucl Eng Des. 2007;237(2):107-23. 